\title{
Author Correction: Genetic relatedness analysis: modern data and new challenges
}

\section{Bruce S. Weir, Amy D. Anderson and Amanda B. Hepler}

Correction to: Nature Reviews Genetics https://doi.org/10.1038/nrg 1960, published online 01 October 2006.

The authors regret an error in Figure 1 and its legend. The last sentence of the legend should be "The calculation of $\theta$ is provided below the figure using $\delta$ or $\Delta$." The equation " $\theta=k_{1} / 2+k_{1} / 4$ " should be changed to " $\theta=k_{2} / 2+k_{1} / 4$, provided $X, Y$ are not inbred." In the example scenario, $X, Y$ are full sibs with first-cousin parents and so they are inbred: their coancestry $\theta$ does not follow from the expression involving only $k$. The authors are grateful for having their error noticed by a reader.

https://doi.org/10.1038/s41576-021-00445-6 I Published online 22 December 2021

(c) Springer Nature Limited 2021 